\title{
Specific brain lesions producing nonspecific (generalized) learning impairments in weanling rats
}

\author{
ROBERT THOMPSON and JEN YU \\ Fairview State Hospital, Costa Mesa, California \\ and University of California Irvine Medical Center, Orange, California
}

\begin{abstract}
Recent studies suggest that lesions to the globus pallidus, lateral thalamus, ventrolateral thalamus, parafascicular thalamus, substantia nigra, or midbrain central gray in adult rats are associated with a nonspecific (generalized) learning impairment. The present study showed that lesions to any one of the foregoing structures, except the ventrolateral and parafascicular thalamus, in 21-day-old rats likewise produce a generalized learning impairment, as evidenced by significant deficits on a white-black discrimination, a nonvisual 11-deg incline-plane discrimination, and a 3-cul maze. A possible brain-injured animal model of mental retardation is discussed.
\end{abstract}

In a 1970 review article on mental retardation in animals, Meier reacted to the available experimental literature on localized brain damage in young animals in the following way:

Nowhere do we see the generalized learning deficits comparable to inferior scholastic performance as we had expected from our knowledge of the behavior of the adult brain-injured. In non-human subjects whatever decrement in performance observed is task-specific and, possibly, modality-specific as well. Brainstem and other forms of subcortical damage may have other significant effects, especially on emotional behaviors, but none which is uniquely and categorically relevant to learning disorders (Meier, 1970, p. 289).

A reaction not unlike Meier's could appropriately be made to reviews of the more recent experimental literature in this area (Isaacson, 1975; Schneider, 1979; St. James-Roberts, 1979).

In considering these rather perplexing findings it should be remembered that the brain sites explored with lesions in young animals, such as the cerebral cortex, hippocampus, and amygdala, are not the ones that play a nonspecific (generalized) role in the learning process in adult animals. Recent lesion experiments on adult rats (Thompson, 1982a, 1982b; Thompson, Gallardo, \& Yu, 1983), for example, have shown that no part of the cerebral cortex or lim-

The completion of this study was facilitated by cooperation of the Board of Directors and Staff of the Rehabilitation Center for Brain Dysfunction. The authors are affiliated with the Department of Physical Medicine and Rehabilitation of the University of California Irvine Medical Center. Requests for reprints should be sent to Robert Thompson, Fairview State Hospital, 2501 Harbor Boulevard, Costa Mesa, California 92626. bic forebrain is essential for normal acquisition of both left-right (vestibular-proprioceptive-kinesthetic) discrimination and white-black (visual) discrimination problems. On the other hand, acquisition of these two tasks was found to be impaired in adult rats with discrete lesions to portions of the "extrapyramidal" system (globus pallidus, substantia nigra, and red nucleus), diencephalon (lateral thalamus, ventrolateral thalamus, parafascicular thalamus, and posterolateral hypothalamus), limbic midbrain area (interpeduncular-central tegmental region, median raphe, and central gray), or pontine reticular formation. (These regions playing a nonspecific role in learning have collectively been termed the "general learning system"; Thompson, 1982a.) Is it possible that selective lesions to the foregoing brain sites in young rats will lead to a nonspecific learning deficit? If so, then the young rat bearing these lesions may conceivably serve as an animal model for certain classes of mental retardation, at least to the extent that both the brain-injured rat and the mental retardate evidence a generalized learning impairment (Denny, 1964).

The initial study in this series (Thompson, Ramsay, $\& \mathrm{Yu}$, in press), which focused on the median raphe and pontine reticular formation, disclosed that weanling (21-day-old) rats prepared with lesions to either one of these brainstem regions were found to be deficient in learning a white-black discrimination, a nonvisual incline plane discrimination, a 3-cul maze, and an array of simple spatial tasks. Since weanling rats with relatively large lateral pontomesencephalic lesions learned each of these tasks as fast as the controls, the generalized learning impairment observed in the presence of median raphe and pontine reticular formation lesions cannot reasonably be explained in 
terms of a nonspecific debilitating effect arising from brainstem damage.

These encouraging results prompted us to carry out the current enterprise, to determine whether discrete lesions to the globus pallidus, lateral thalamus, ventrolateral thalamus, parafascicular thalamus, substantia nigra, or midbrain central gray in weanling rats would likewise produce a generalized learning impairment. (Data on the red nucleus and posterolateral hypothalamus, the remaining components of the general learning system, are not presented because of the high mortality rate associated with injuries to these regions in weanling rats.) Specifically, weanling rats receiving selective lesions to these structures or sham operations were first required to learn a white-black discrimination. Following learning of this problem, the animals were blinded by enucleation and subsequently were required to learn an incline-plane discrimination. Data on acquisition of a 3-cul maze are also included. For comparative purposes, weanling rats with dorsal hippocampal lesions were also studied. (Lesions of the dorsal hippocampus in adult rats do not produce deficient acquisition of a white-black discrimination problem; Sara \& David-Remacle, 1981; Thompson, 1982a.)

At this juncture, it should be pointed out that we have been unsuccessful in keeping neonatal (or even 10-day-old) rats alive in the presence of lesions to some of the foregoing brainstem structures. While the use of neonatal subjects would be more relevant to developmental psychobiology than would the use of weanling subjects, information gathered on the latter is regarded as being better than no information at all.

\section{METHOD}

\section{Discrimination Habits}

\section{Subjects and Surgery}

A total of 106 weanling (21-day-old) male Sprague-Dawley albino rats, 38-55 g, underwent surgery under deep chloral hydrate anesthesia $(400 \mathrm{mg} / \mathrm{kg})$. All lesions were accomplished electrolytically (in one stage) by passing a constant anodal current of 1.01.8 mA for a duration of 8-10 sec through an implanted stainless steel electrode with $1.0 \mathrm{~mm}$ of the tip exposed. Seven groups sustained bilateral lesions to either the globus pallidus (Group GP), lateral thalamus (Group LT), ventrolateral thalamus (Group VLT), parafascicular thalamus (Group PFT), substantia nigra (Group SN), midbrain central gray (Group CG), or dorsal hippocampus (Group DH). The eighth group (Group C) served as sham-operated controls, undergoing the same surgical procedure as the experimental groups, except for insertion of the lesion electrode and the application of current.

Postoperatively, all animals were usually housed, two per cage, in medium-sized wire cages containing a constant supply of food pellets and water. During the first postoperative week, a dish of fresh sweetened wet mash was placed daily in each cage. Throughout the recovery period, the animals were handled for approximately 5 min on every 3rd day. Preliminary training began 3 weeks after surgery. On the day prior to preliminary training, the vibrissae of each animal were shaved (see Thompson, 1982a).

\section{Apparatus}

Visual discrimination. A two-choice Thompson-Bryant discrimination box, utilizing the motive of escape-avoidance of footshock, was employed (see Thompson, 1978). Two pairs of stimulus cards were used in the apparatus. One pair (two medium gray cards) was employed in training the animals to displace a card in order to gain access to the goalbox. The second pair consisted of a white card and a black card.

Incline-plane discrimination. A single-unit T-maze, modified for escape-avoidance of footshock, was employed to establish the incline-plane (vestibular-proprioceptive-kinesthetic) discrimination habit (see Thompson, 1978, and Thompson, Arabie, \& Sisk, 1976). The stem of the $T$ served as the startbox, and the left and right arms constituted the choice chamber. At the end of each arm was a window through which the rat could enter the endbox. During formal training, a black card mounted on a wooden block was placed against each window. The entire apparatus was secured to a platform that could be tilted 11 deg laterally.

\section{Procedure}

All animals were initially required to learn the visual discrimination problem. Following learning, the animals were blinded by enucleation under deep chloral hydrate anesthesia and were subsequently required to learn the incline-plane discrimination problem. Throughout the experiment, the animals were run "blind"-the experimenter had no knowledge as to which group each subject belonged.

Visual discrimination. On Day 1, each rat was allowed to explore the goalbox for $10 \mathrm{~min}$. Subsequently, the rat was placed in a restraining cage for $10 \mathrm{~min}$, after which it was returned to the home cage.

On Day 2, each rat was trained to run into the choice chamber from the startbox, displace one of the cards blocking the window, and enter the goalbox in order to escape from (or avoid) footshock.

On Day 3, training on the visual discrimination was begun. An approach response to the unlocked white (positive) card admitted the animal to the goalbox. On the other hand, an approach response to the adjacent locked black (negative) card was automatically punished by footshock, with the animal subsequently being forced to respond to the white card in order to gain entrance into the goalbox. An error was defined as an approach response to the black card which brought the animal's forefeet in contact with the charged grid section, which extended $8.0 \mathrm{~cm}$ in front of the negative card. The position of the positive (and negative) card was switched from the right to the left window in a sequence mixed with single- and double-alternation runs. Usually, 8-10 trials were given each day with an intertrial interval of $50-75 \mathrm{sec}$. The criterion of learning consisted of the first appearance of either a "perfect" or "near-perfect" run of correct responses having a probability of occurrence of less than .05 (Runnels, Thompson, \& Runnels, 1968), followed by at least $75 \%$ correct responding in the subsequent block of 8 trials given on the next day. In a few instances, the criterion was not reached within 100 trials, but the animals (and their respective trial and error scores) were considered to have met criterion on the 100th trial.

The specific training procedure was as follows: The animal was placed in the startbox and the startbox door was raised. Failure to leave the startbox within $5 \mathrm{sec}$ was followed by footshocks until the animal entered the choice chamber. No further footshocks were given unless the animal made an error or failed to respond to one of the cards within $5 \mathrm{sec}$. The animal was allowed to remain in the goalbox for $10 \mathrm{sec}$, after which it was transferred to the restraining cage to await the next trial. The animals were usually run in squads of two.

Incline-plane discrimination. On the day following the attainment of the criterion of learning on the visual problem, the animals were habituated to each endbox of the T-maze for $5 \mathrm{~min}$ and then trained to run into one of the arms from the startbox, displace the card blocking the window, and enter the endbox in order to escape from (or avoid) footshock. During this period, the appa- 
ratus was in the horizontal position. One hour later, the animals were blinded by enucleation.

On the following day, the animals were trained on the inclineplane problem. An approach response to the upward sloping arm led to an endbox that could be entered by displacing the unlocked card, whereas an approach response to the downward sloping arm led to a locked card that prevented the animal from entering the endbox on that side. Punishment for an error (approach to within $10.8 \mathrm{~cm}$ of the locked card) was given by charging the grid section located below the locked card. The position of the correct (and incorrect) arm was switched from the right to the left side in a sequence mixed with single- and double-alternation runs; 8-10 trials were usually given each day with an intertrial interval of $50-75 \mathrm{sec}$. The criterion of learning and the specific training procedure were the same as those described for the visual discrimination problem. When the criterion of learning was not met within 64 trials, training was terminated at that point.

\section{Histology}

At the conclusion of postoperative testing, each brain-damaged rat was killed with an overdose of chloral hydrate, its vascular system was perfused with normal saline followed by $10 \%$ Formalin, and the brain was removed and stored in 10\% Formalin for $2-4$ days. Each brain was then blocked, frozen, and sectioned frontally at 90 microns. Every fourth section through the lesioned area was retained and subsequently photographed at $12 \times$ by using the section as a negative film in an enlarger (see Thompson, 1971).

\section{Measures of Performance}

Performance measures were trials to criterion and initial errors to criterion. In addition, a third measure (total errors to criterion) was also included because it was not uncommon for an animal to retreat from the charged grid section below the locked card and then to approach the locked card a second (third, fourth, etc.) time, each approach response resulting in footshock. Thus, total errors to criterion involved the sum of approaches to the locked card that resulted in footshock.

The differences in mean performance scores between each braindamaged group and the control group were evaluated by the MannWhitney U test. Since our prediction was that the former would be inferior to the latter, a one-tailed test was used.

\section{Maze Habit}

After the completion of the foregoing experiment, it was decided to determine whether those lesion placements significantly impairing acquisition of both the visual and incline-plane discrimination problems would also impair acquisition in a 3-cul maze that utilized the motive of escape-avoidance of footshock. The true path, which measured $120.5 \mathrm{~cm}$ from the startbox exit to the goalbox entrance, consisted of a 90-deg turn to the left (avoiding the first cul), a 180-deg turn to the right (avoiding the second and third culs), followed by a 90-deg turn to the left (see Thompson, 1978). The apparatus was located in a sound-attenuated room that was illuminated by conventional ceiling fluorescent lights. No effort was made to control for intramaze olfactory cues or any extramaze cues.

Data are reported on 29 rats that received either subcortical lesions or sham operations at the age of 21-23 days. Following a 6-week recovery period, each animal was initially given preliminary training in the Thompson-Bryant discrimination box to develop and shape efficient escape-avoidance responses to footshock. On the following day, each animal was habituated to the goalbox of the maze for $5 \mathrm{~min}$. Then it was placed in the startbox and the startbox door was raised. Failure to leave the startbox within 5 sec was followed by footshocks. No further footshocks were given unless the animal made an error (entered a blind alley by at least the length of its head and thorax) or stopped forward progression in the maze. Upon entering the goalbox, a guillotine door was lowered to prevent reentry into the maze. The animal was permitted to remain in the goalbox for $10 \mathrm{sec}$, after which it was transferred to a restraining cage to await the next trial. Four trials were given daily with an intertrial interval of $50-75 \mathrm{sec}$. Training was terminated when the animal made no more than one error in 2 consecutive days. Both initial and repetitive (reentries into culs) errors were recorded. Histological verification of the location of the lesions was accomplished at the conclusion of postoperative testing.

\section{RESULTS}

\section{Discrimination Habits}

Of the original 106 rats undergoing surgery, 31 died prior to the onset of the learning tests, the highest mortality rate occurring in Groups GP and SN. An additional 20 rats were excluded from the experiment because their lesions were either too small, grossly asymmetrical, or distant from the intended target area.

\section{Learning}

Table 1 summarizes the mean performance scores for all groups on the visual and incline-plane discrimination problems. These results will be discussed in terms of the site of brain damage.

Group C. All sham-operated controls succeeded in reaching the criterion of learning on the visual problem within 54 trials (excluding the criterion run) and on the incline-plane problem within 36 trials. In terms of trials (errors) to criterion, the Wilcoxon test for paired replicates disclosed that the visual problem was significantly more difficult to master than the incline-plane problem (ps $<.01$, two-tailed test).

Group GP. Five rats sustained relatively discrete lesions to the globus pallidus like the one shown in Figure 1. As noted in Table 1, these animals were significantly retarded in learning both discrimination tasks.

Group LT. The lateral dorsal and lateral posterior thalamic nuclei were extensively damaged in four rats. Figure 2 shows a representative lesion to this thalamic area. As a group, these animals were significantly impaired in learning both problems. Two of these animals failed to reach the criterion of learning on the incline-plane problem within 64 trials.

Group VLT. Five rats received relatively small thalamic lesions which were largely confined to the ventrolateral nucleus, such as the one shown in Figure 3. While these animals tended to learn the visual problem more slowly than the controls, the differences in performance measures failed to reach statistical significance. However, performance on the incline-plane problem was significantly inferior to that of the controls. One of these animals failed to master the incline-plane problem within the limits of training. 
Table 1

Mean Learning (Trial and Error) Scores for All Groups

\begin{tabular}{|c|c|c|c|c|c|c|c|}
\hline \multirow[b]{2}{*}{ Group } & \multirow[b]{2}{*}{$\mathrm{N}$} & \multicolumn{2}{|c|}{ Trials } & \multicolumn{2}{|c|}{ Initial Errors } & \multicolumn{2}{|c|}{ Total Errors } \\
\hline & & Mean & Range & Mean & Range & Mean & Range \\
\hline \multicolumn{8}{|c|}{ Visual Discrimination } \\
\hline $\mathrm{C}$ & 11 & 37.5 & $23-54$ & 19.0 & $12-30$ & 24.9 & $17-36$ \\
\hline GP & 5 & $55.4^{*}$ & $41-67$ & $25.8^{*}$ & $21-19$ & $34.4 *$ & $31-42$ \\
\hline LT & 4 & 48.5 & $32-68$ & $24.7 *$ & $16-31$ & $33.5^{*}$ & $23-43$ \\
\hline VLT & 5 & 53.0 & $30-100$ & 25.4 & $16-40$ & 30.6 & $19-48$ \\
\hline PFT & 12 & 44.6 & $21-100$ & 19.0 & $9-36$ & 27.3 & $15-42$ \\
\hline SN & 4 & $60.0^{*}$ & $42-100$ & 28.2 & $18-45$ & 34.2 & $19-58$ \\
\hline CG & 4 & $53.5^{*}$ & $38-71$ & 23.5 & $18-29$ & 30.7 & $25-37$ \\
\hline $\mathrm{DH}$ & 10 & 40.4 & $22-71$ & 18.3 & $10-26$ & 27.7 & $21-38$ \\
\hline \multicolumn{8}{|c|}{ Incline Plane Discrimination } \\
\hline $\mathrm{C}$ & 11 & 17.5 & $10-36$ & 9.2 & $6-14$ & 10.9 & $6-15$ \\
\hline GP & 5 & $28.8^{*}$ & $21-41$ & $12.2 *$ & $9-16$ & $14.0 *$ & $11-18$ \\
\hline LT & 4 & $46.7^{*}$ & $25-64$ & $21.0 *$ & $11-30$ & $24.0 *$ & $11-39$ \\
\hline VLT & 5 & $39.4 *$ & $15-64$ & $24.7 *$ & $8-30$ & $27.5^{*}$ & $10-30$ \\
\hline PFT & 12 & $38.3^{*}$ & $21-64$ & $18.5 *$ & $7-33$ & $21.3 *$ & $9-38$ \\
\hline SN & 4 & $56.5^{*}$ & $26-64$ & $25.0 *$ & $16-30$ & $30.0 *$ & $18-38$ \\
\hline CG & 4 & $45.5^{*}$ & $22-64$ & $24.3 *$ & $14-35$ & $26.5 *$ & $18-35$ \\
\hline DH & 10 & $34.0 *$ & $15-64$ & $16.5^{*}$ & $7-32$ & $18.1^{*}$ & $9-32$ \\
\hline
\end{tabular}

${ }^{*}$ Differed from the controls at least at the .05 level (one-tailed test).

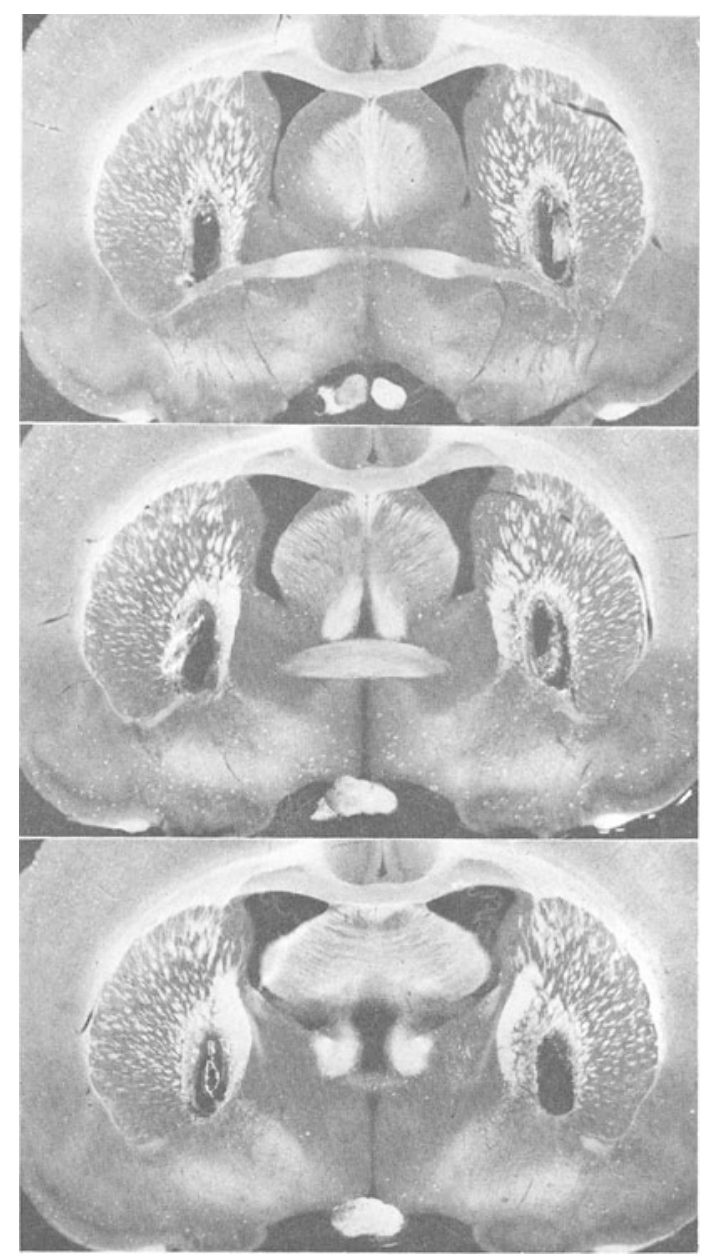

Figure 1. Photographs of unstained sections showing a lesion to the globus pallidus in one rat.

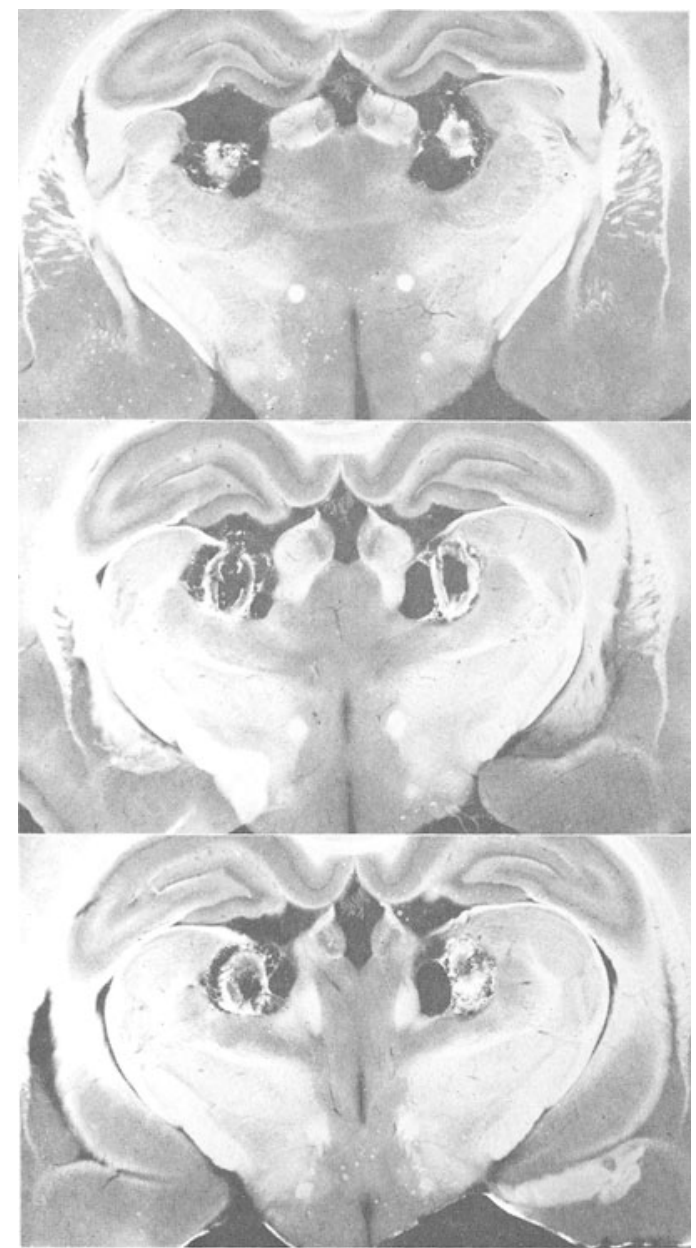

Figure 2. Photographs of unstained sections showing a lesion to the lateral thalamus in one rat. 


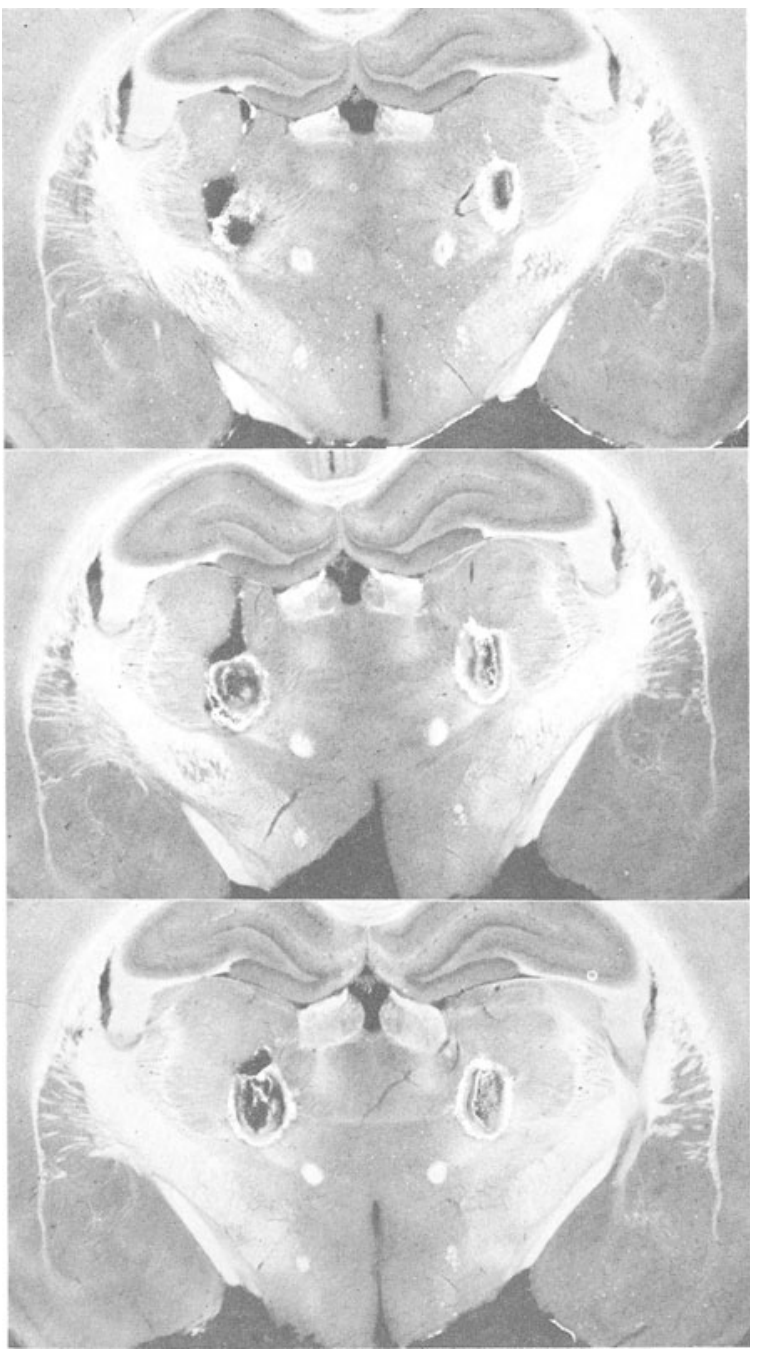

Figure 3. Photographs of unstained sections showing a lesion to the ventrolateral thalamus in one rat.

Group PFT. The parafascicular nucleus and the habenulopeduncular tract were damaged in 12 rats. In most cases, the pretectal area and the posterior portion of the mediodorsal thalamic nucleus were also injured. A typical lesion is shown in Figure 4. As in the case of Group VLT, these animals showed no significant deficit on the visual problem, but were significantly impaired on the incline-plane problem. Two of these rats failed to reach the criterion of learning on the latter problem.

Group SN. Four rats sustained relatively discrete lesions to the lateral portion of the substantia nigra. In all cases, the underlying cerebral peduncle was slightly invaded. Figure 5 shows a representative lesion to this midbrain area. These animals were significantly inferior to the controls (at least in terms of trial scores) in acquiring both discrimination habits.

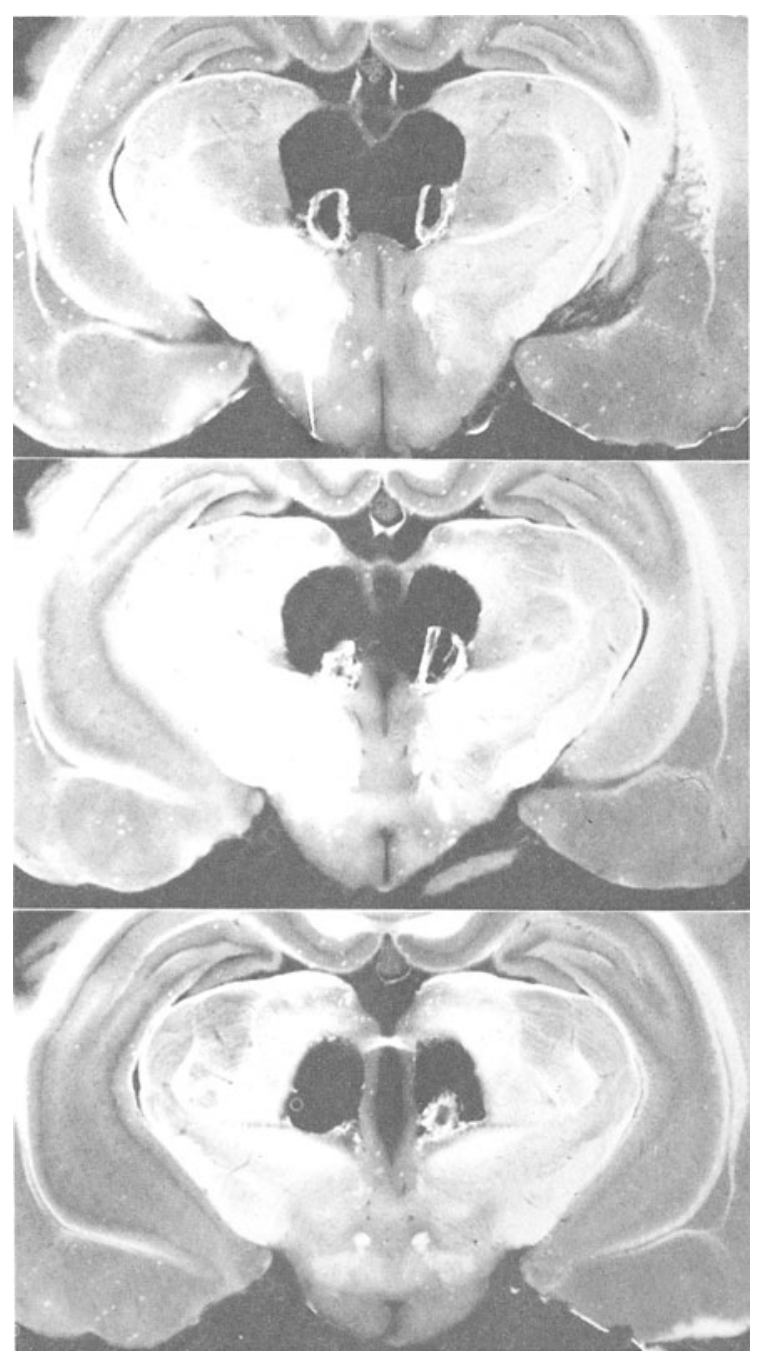

Figure 4. Photographs of unstained sections showing a lesion to the parafascicular thalamus in one rat.

One of these animals failed to learn either problem within the limits of training, and two other animals were unable to learn the incline-plane problem within 64 trials.

Group CG. Four rats were subjected to extensive damage to the midbrain central gray. In most instances, the overlying superior colliculus and adjacent reticular formation were only slightly injured (see Figure 6). In terms of at least one measure of performance, this group was found to be significantly retarded in acquiring both discrimination tasks.

Group DH. The dorsal hippocampus was the target of multiple electrolytic lesions in 10 rats. In most cases, such as the one shown in Figure 7, the overlying medullary substance was damaged, but the subjacent thalamus was largely spared. These animals were virtually indistinguishable from the controls in ac- 


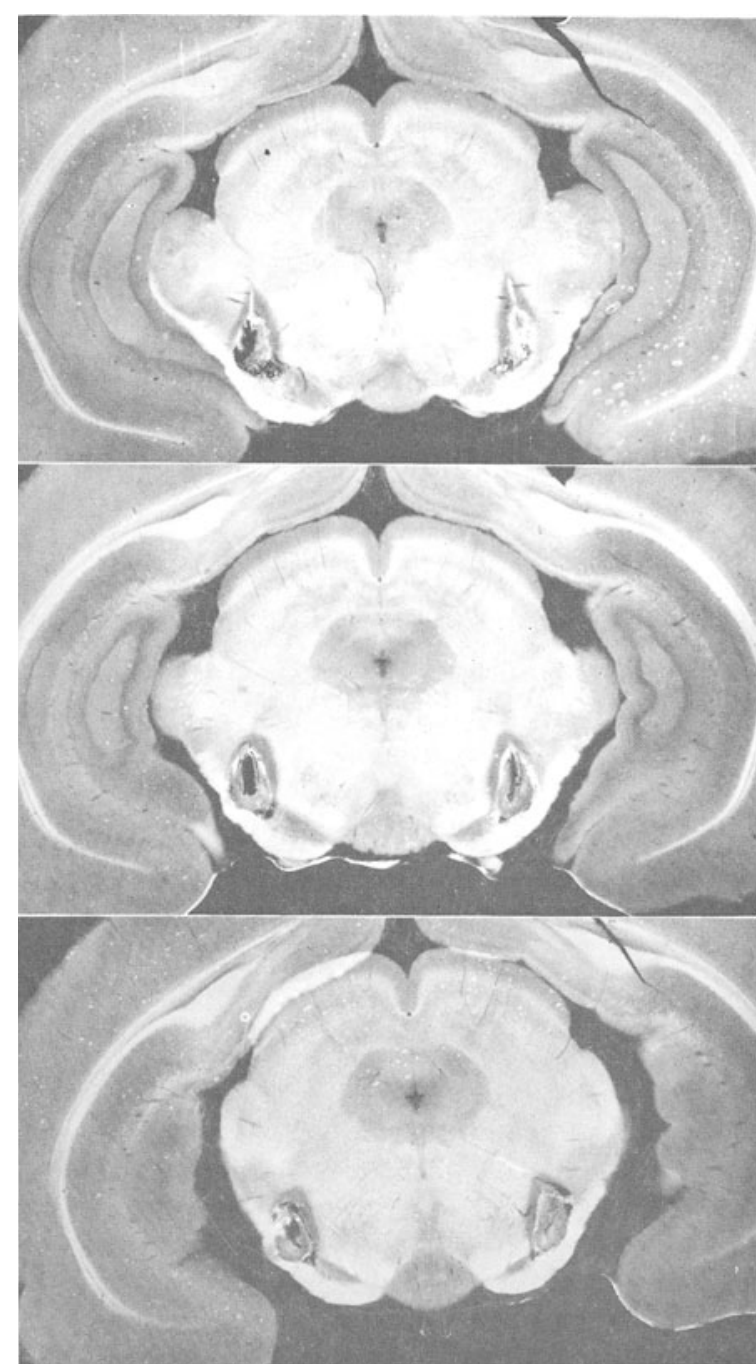

Figure 5. Photographs of unstained sections showing a lesion to the substantia nigra in one rat.

quiring the visual problem, but were significantly impaired in acquiring the incline-plane problem. One of these animals failed to reach the criterion of learning on the latter problem.

\section{Other Observations}

Body weight. All animals were weighed after a 3-week recovery period. Only those groups with pallidal (mean and standard error $=121.8 \pm 7.3 \mathrm{~g}$ ), ventrolateral thalamic $(131.0 \pm 6.1 \mathrm{~g})$, and nigral (119.0 $\pm 14.0 \mathrm{~g}$ ) lesions weighed significantly (ps $<.05$, twotailed test) less than the controls $(160.6 \pm 6.9 \mathrm{~g})$. The weights of the remaining groups were $187.8 \pm 12.0 \mathrm{~g}$ (Group LT), $150.7 \pm 7.1 \mathrm{~g}$ (Group PFT), $155.6 \pm 6.5 \mathrm{~g}$ (Group CG), and 174.1 $\pm 3.6 \mathrm{~g}$ (Group DH).

General health and behavior. Disregarding the relative size of the subjects, all brain-damaged (and control) rats appeared healthy and alert at the time of

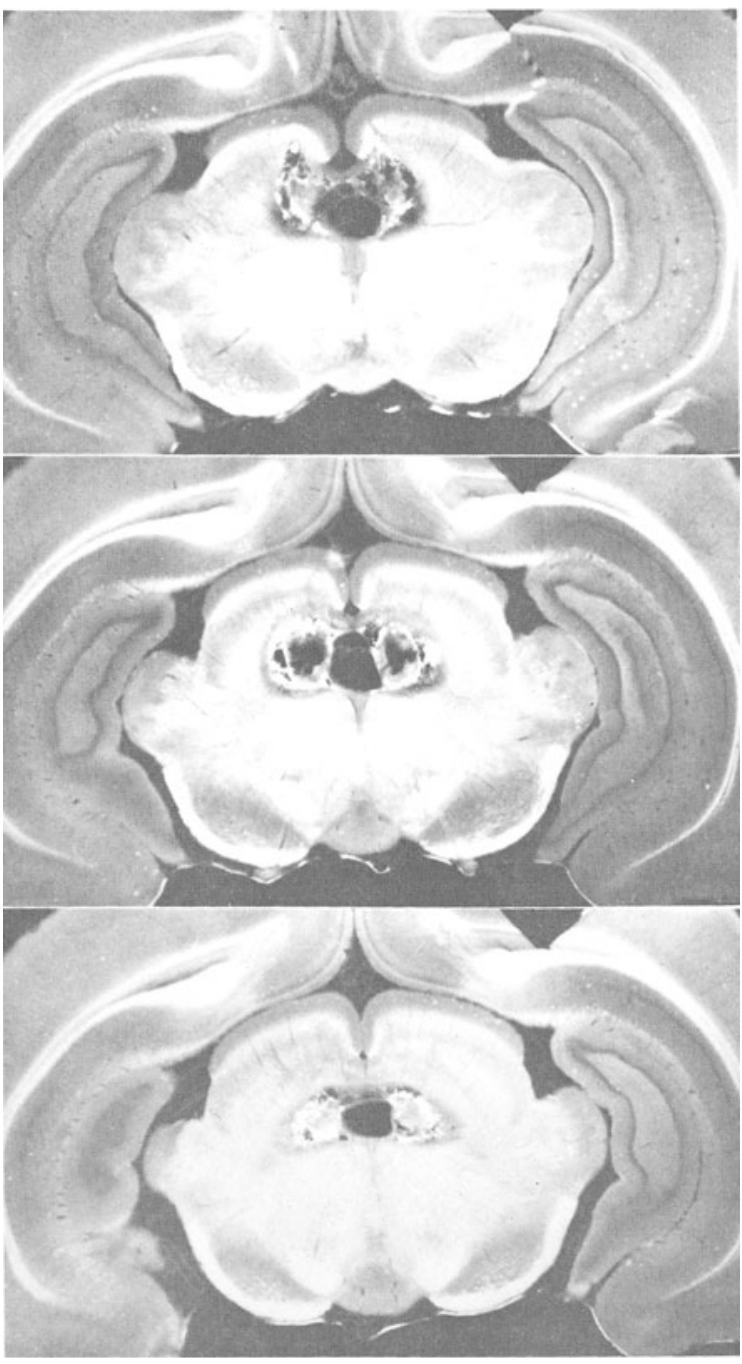

Figure 6. Photographs of unstained sections showing a lesion to the midbrain central gray in one rat.

the visual discrimination test. The five animals (two with pallidal and three with nigral lesions) that showed eating and drinking disturbances beyond the second postsurgical day gradually recovered these behaviors, especially in the presence of a bowl of sweetened wet mash. Curiously, it was noted that three of the four rats with nigral lesions had at least two toes missing from one of their forepaws. ${ }^{1}$

Escape-avoidance behavior. All of the controls and most of the brain-damaged rats readily entered the choice chamber from the startbox and proceeded toward the goalbox (or endbox) either without footshock or with the application of one or two footshocks. Only eight animals (seven from Group PFT and one from Group $\mathrm{SN}$ ) required more than the usual number of footshocks to force escape responses during training on the visual and incline-plane tasks. In addition, eight animals (six from Group PFT, one from Group VLT, and one from Group GP) appeared 




Figure 7. Photographs of unstained sections showing multiple lesions to the dorsal hippocampus in one rat.

"reluctant" to push open the white card in order to gain entrance into the goalbox-it was necessary for the experimenter to displace the card to allow the animal to enter the goalbox.

A more commonly observed "aberrant" escape- avoidance response (which appeared mainly in the visual discrimination apparatus) consisted of extremely rapid (ballistic) running from the startbox toward the goalbox. This was seen in 8 control rats and in 18 brain-damaged rats (1 from Group SN, 2 from Group GP, 2 from Group LT, 2 from Group PFT, 3 from Group VLT, 4 from Group CG, and 4 from Group $\mathrm{DH}$ ). By routinely imposing a delay of $10-20 \mathrm{sec}$ between inserting the animal into the startbox and raising the startbox door, it was possible to reduce running speed in these animals.

\section{Maze Habit}

As shown in Table 2, those groups sustaining lesions to the globus pallidus, lateral thalamus, substantia nigra, or midbrain central gray exhibited a significant deficit in acquiring the 3-cul maze habit in terms of at least one measure of performance. (Lesions of the ventrolateral thalamus, parafascicular nucleus, and dorsal hippocampus were not investigated because they failed to impair acquisition of both the visual and the incline-plane discrimination problems.) The lesions suffered by Groups SN and CG were largely comparable to those examined in connection with learning of the two discrimination habits. With respect to Group GP, the lesions tended to be somewhat more lateral than the one shown in Figure 1. In the case of Group LT, the lesions tended to be slightly more anterior and ventral (damaging portions of the ventrolateral thalamic nucleus) than the one shown in Figure 2.

When weighed at 42 days of age, Group GP (135.8 $\pm 8.0 \mathrm{~g})$ and Group SN $(126.4 \pm 11.4 \mathrm{~g})$ were significantly (ps $<.05$, two-tailed test) lighter than the controls $(167.6 \pm 6.7 \mathrm{~g})$. Although Groups LT (127.8 \pm $15.5 \mathrm{~g})$ and CG $(142.8 \pm 10.0 \mathrm{~g})$ were also lighter than the controls, neither difference approached statistical significance.

All animals appeared healthy and alert at the time of the acquisition test and all exhibited excellent escape-avoidance responses in the maze. Six of the eight rats in Group SN had at least two toes missing from one of their forepaws.

Table 2

Mean Learning (Trial and Error) Scores for All Groups on the Maze Habit

\begin{tabular}{|c|c|c|c|c|c|c|c|}
\hline \multirow[b]{2}{*}{ Group } & \multirow[b]{2}{*}{$\mathbf{N}$} & \multicolumn{2}{|c|}{ Trials } & \multicolumn{2}{|c|}{ Initial Errors } & \multicolumn{2}{|c|}{ Total Errors } \\
\hline & & Mean & Range & Mean & Range & Mean & Range \\
\hline $\mathrm{C}$ & 9 & 5.3 & 4- 8 & 5.9 & $3-11$ & 8.0 & $5-14$ \\
\hline GP & 4 & $10.0^{*}$ & 8- 12 & 6.3 & 4- 8 & 9.8 & $5-14$ \\
\hline LT & 4 & $12.0^{*}$ & $8-20$ & $16.3^{*}$ & $9-32$ & $21.5^{*}$ & $12-46$ \\
\hline SN & 8 & $13.5^{*}$ & 8- 32 & 9.9* & $6-14$ & $12.6^{*}$ & $7-25$ \\
\hline CG & 4 & $10.0^{*}$ & $8-12$ & $13.3^{*}$ & $8-17$ & $21.3^{*}$ & $11-33$ \\
\hline
\end{tabular}

*Differed from the controls at least at the .05 level (one-tailed test). 


\section{DISCUSSION}

\section{General Findings}

It has previously been reported that weanling rats subjected to median raphe or pontine reticular formation lesions are deficient in acquiring a variety of laboratory tasks, including visual and nonvisual discrimination problems, a 3-cul maze, and a series of simple spatial habits (Thompson et al., in press). According to the results of the current study, weanling rats with lesions to the globus pallidus, lateral thalamus, substantia nigra, or midbrain central gray also exhibit what appears to be a generalized learning impairment, as evidenced by deficient acquisition of a white-black discrimination, an 11-deg incline-plane discrimination, and a 3-cul maze. These findings are inexplicable in terms of the presence of any nonspecific debilitating effects arising from brain damage in the weanling rat. In the current expriment, for example, the group with extensive dorsal hippocampal damage, although impaired in learning the inclineplane problem, earned excellent performance scores on the visual problem. Moreover, weanling rats with relatively large lesions to the lateral portions of the brainstem at pontomesencephalic levels have been reported to learn both of these discrimination problems (as well as the maze habit) as fast as sham-operated controls (Thompson et al., in press).

While the foregoing results on weanling rats are in accord with earlier lesion studies on adult rats (Thompson, 1982a, 1982b; Thompson et al., 1983), the findings relative to damage to the ventrolateral thalamus and the parafascicular thalamus are not. Our weanling rats sustaining ventrolateral or parafascicular thalamic lesions, unlike adult rats with these lesions (Thompson, 1982a, 1982b), failed to exhibit a significant learning impairment on the visual discrimination problem, although they did exhibit a significant learning impairment on the incline-plane discrimination problem. One possible explanation of this discrepancy may lie in the fact that the adult rats examined in the earlier study sustained appreciably larger lesions to these thalamic regions than those sustained by the weanling rats of the present study. This explanation, however, tends to suffer from the finding that our weanling rats with "small" ventrolateral or parafascicular thalamic lesions were seriously impaired in acquiring the incline-plane problem, even though this habit is considerably easier to master (by control rats) than is the visual habit. Furthermore, it is important to note that the pallidal and nigral lesions received by our weanling rats were likewise smaller than those received by adult rats (see Thompson, 1982a, 1982b), and yet the former still produced significant learning deficits on both the visual and incline-plane problems.
Alternatively, this discrepancy could seemingly be interpreted within the context of either greater plasticity of the weanling brain in comparison with that of the adult brain (McWilliams \& Lynch, 1983) or delayed behavioral manifestations of early brain damage (Goldman, 1974). These notions, however, may not be reasonably applicable to the discrepancy under discussion when it is considered that our weanling rats with pallidal, lateral thalamic, nigral, central gray, median raphe, or pontine reticular formation lesions did, in fact, exhibit significant retardation in learning the visual (as well as the incline-plane) discrimination habit.

Whatever the cause of this discrepancy, these data on the ventrolateral and parafascicular thalamus tend to limit the generality of the assumption that those lesion placements producing a generalized learning loss in adult rats will also produce a generalized learning loss in young rats.

One rather surprising result emerging from this study deals with the substantial learning impairment on the incline-plane problem in those rats with dorsal hippocampal damage. Adult rats that have been trained preoperatively on the incline-plane problem do not exhibit a significant retention deficit following extensive damage to the dorsal hippocampus (Thompson et al., 1976). While no corresponding data on adult rats have been reported in relation to acquisition of this discrimination, Gittelson and Donovick (1968) found that adult rats with septal lesions learn an incline-plane problem about as fast as do controls. This pattern of results is of considerable interest, but it will remain refractory to explanation until further information is available on the effects of hippocampal lesions in adult rats on acquisition of the incline-plane discrimination problem.

\section{Anatomical and Functional Considerations}

While the overall data derived from our recent studies of weanling and adult rats suggest that selective lesions to the globus pallidus, lateral thalamus, substantia nigra, midbrain central gray, median raphe, and pontine reticular formation are associated with a generalized learning impairment, they lack the precision necessary to identify the specific elements within each of these structures that may play a significant role in the general learning process. This, of course, is due to the fact that typical electrolytic lesions to the brain destroy perikarya as well as fiber systems. This complication, however, does not seriously detract from our previous interpretation regarding the functional significance of these structures in learning, since we do not ascribe specific functions to specific parts of the brain. As discussed elsewhere (Thompson, 1982b, in press), the foregoing subcortical regions, collectively termed the "general 
learning system," are conceived as a functional entity that serves to mobilize the activities of the brain for the task at hand (e.g., assists in the engagement of the appropriate specific mechanisms ${ }^{2}$ ), possibly through the intervention of a complex attentional process. The evidence favoring this conceptualization is admittedly scant and subject to other interpretations. However, it does have the virtue of providing a framework within which the results of a wide range of lesion studies on animal learning and memory can be interpreted (see Thompson, 1983).

\section{A Possible Animal Model of Mental Retardation}

One of the distinguishing features of mental retardation in the young human is the presence of a global learning defect (Denny, 1964). Since brain damage in the adult human is most often accompanied by specific neuropsychological deficits (Russell, 1981), it is generally held that certain classes of mental retardation arise from early insult to a progressively differentiating mammalian brain. However, the study of circumscribed brain injuries in young animals has not supported this view. Discrete lesions to the cerebral cortex or limbic forebrain in young animals, for example, do not produce a generalized learning impairment (Isaacson, 1975; Meier, 1970). Even prenatal induction of microcephaly in rats has not consistently led to a generalized learning impairment (Rabe \& Haddad, 1972; Tamaki \& Inouye, 1976).

One likely reason for the failure to observe a generalized learning loss in the young brain-damaged animal (and for the consequent failure to develop a brain-damaged animal model of mental retardation) is that the brain sites explored with lesions (e.g., cerebral cortex and limbic forebrain) are not the ones that participate either directly or indirectly in the general learning process in the adult animal (Thompson, 1982a, 1982b; Thompson et al., 1983). As shown in the present study (see also Thompson et al., in press), a generalized learning loss may be observed in the young brain-damaged rat provided that the targets for the lesion placements involve certain brainstem structures that are implicated in the general learning process in the adult rat.

Although providing remarkable support for the view that there is a brainstem involvement in mental retardation (Buchwald, 1975), it is difficult to determine at the present time whether these results on the laboratory rat will prove to be generalizable across different mammalian species. For this reason, the use of the young brain-injured rat (one with lesions to the general learning system) as an experimental model for the study of certain types of mental retardation remains in doubt. If, however, an attentional defect is found to contribute to the generalized learning impairments observed in our experiments, ${ }^{3}$ then a reasonable parallel between the learning disabilities of our brain-injured rats and those exhibited by mental retardates could exist, at least to the extent that the latter have likewise been attributed to some kind of attentional defect (Denny, 1964; Zeaman \& House, 1979).

\section{REFERENCES}

BuCHWALD, J. S. Brainstem substrates of sensory information processing and adaptive behavior. In N. A. Buchwald \& M.A.B. Brazier (Eds.), Brain mechanisms in mental retardation. New York: Academic Press, 1975.

Denny, M. R. Research in learning and performance. In H. A. Stevens \& R. Heber (Eds.), Mental retardation. Chicago: University of Chicago Press, 1964.

Gitelelson, P.L., \& Donovick, P. J. The effects of septal lesions on the learning and reversal of a kinesthetic discrimination. Psychonomic Science, 1968, 13, 137-138.

Goldman, P. S. An alternative to developmental plasticity: Heterology of CNS structures in infants and adults. In D. G. Stein, J. J. Rosen, \& N. Butters (Eds.), Plasticity and recovery of function in the central nervous system. New York: Academic Press, 1974.

HASSLE R, R. Interaction of reticular activating systems for vigilance and truncothalamic and pallidal systems for directing awareness and attention under striatal control. In P. A. Buser \& A. Rougeul-Buser (Eds.), Cerebral correlates of conscious experience. Amsterdam: North Holland, 1978.

IsAACson, R. L. The myth of recovery from brain damage. In N. R. Ellis (Ed.), Aberrant development in infancy. Hillsdale: Erlbaum, 1975.

McWilliams, J. R., \& LYNCh, G. Role of synaptic replacement in denervated rat hippocampus declines precipitously from the juvenile period to adulthood. Science, 1983, 221, 572-574.

Meier, G. W. Mental retardation in animals. International Review of Research in Mental Retardation, 1970, 4, 263-309.

RABE, A., \& HADdAD, R. K. Methylazoxymethanol-induced microcephaly in rats: Behavioral studies. Federation Proceedings, 1972, 31, 1536-1539.

Ray, C. L., Mirsky, A. F., \& Pragay, E. B. Functional analysis of attention-related unit activity in the reticular formation of the monkey. Experimental Neurology, 1982, 77, 544-562.

Runnels, L. K., Thompson, R., \& Runnels, P. Near-perfect runs as a learning criterion. Journal of Mathematical Psychology, 1968, 5, 362-368.

RUSSELl, E. W. The pathology and clinical examination of memory. In S. B. Filskov \& T. J. Boll (Eds.), Handbook of clinical neuropsychology. New York: Wiley, 1981.

SARA, S. J., \& DAvid-Remacle, M. Discrimination avoidance learning in hippocampal and cortical rats: Acquisition rate, behavioral strategies, and long-term retention. Physiological Psychology, 1981, 9, 37-48.

Schneide R, G. E. Is it really better to have your brain lesion early? A revision of the "Kennard principle." Neuropsychologia, 1979, 17, 557-583.

St. James-Roberts, I. Neurological plasticity, recovery from brain insult, and child development. Advances in Child Development and Behavior. 1979, 14, 253-319.

TAMAKI, Y., \& INOUYE, M. Brightness discrimination learning in a Skinner box in prenatally $\mathrm{X}$-irradiated rats. Physiology \& Behavior, 1976, 16, 343-348.

Tномpson, R. Introducing subcortical lesions by electrolytic methods. In R. D. Myers (Ed.), Methods in psychobiology (Vol. 1). New York: Academic Press, 1971.

Thompson, R. A behavioral atlas of the rat brain. New York: Oxford University Press, 1978.

Thомpson, R. Brain lesions impairing visual and spatial reversal learning in rats: Components of the "general learning system" 
of the rodent brain. Physiological Psychology, 1982, 10, 186-198. (a)

Thompson, R. Impaired visual and spatial reversal learning in brain-damaged rats: Additional components of the "general learning system" of the rodent brain. Physiological Psychology, $1982,10,293-305$ (b)

Thompson, R. Functional organization of the rat brain. In J. Orbach (Ed.), Neuropsychology after Lashley. Hillsdale, N.J: Erlbaum, 1982. (c)

Thompson, R. Brain systems and long-term memory. Behavioral and Neural Biology, 1983, 37, 1-45.

Thompson, R. Nonspecific neural mechanisms involved in learning and memory in the rat. In N. Butters \& L. Squire (Eds.), Neuropsychology of memory. New York: Guilford Press, in press.

Thompson, R., Arabie, G. J., \& Sisk, G. B. Localization of the "incline plane discrimination memory system" in the white rat. Physiological Psychology, 1976, 4, 311-324.

Thompson, R., Gallardo, K., \& Yu, J. Posterolateral hypothalamic and midbrain central gray lesions impair visual and spatial reversal learning: Further additions to the "general learning system" of the rodent brain. Physiological Psychology, 1983, 11, 93-102.

Thompson, R., Ramsay, A., \& YU, J. A generalized learning deficit in albino rats with early median raphe and pontine reticular formation lesions. Physiology \& Behavior, in press.

Wall, P. D., Devor, M., Inbal, R., Scadding, J. W., Schonfeld, D., Seltzer, Z., \& Tomkiewiez, M. M. Autotomy following peripheral nerve lesions: Experimental anesthesia dolorosa. Pain, 1979, 7, 103-113.

Wallesch, C. W., Kornhuber, H. H., Kunz, T., \& Brunner, R. J. Neuropsychological deficits associated with small unilateral thalamic lesions. Brain, 1983, 106, 141-152.
Wirtshafter, D., \& Asin, K. E. Evidence that electrolytic median raphe lesions increase locomotion but not exploration. Physiology \& Behavior, 1982, 28, 749-754.

Zeaman, D., \& House, B. J. A review of attention theory. In N. R. Ellis (Ed.), Handbook of mental deficiency, psychological theory and research (2nd ed.). New York: Wiley, 1979.

\section{NOTES}

1. Rats with severed dorsal roots or peripheral nerves have been observed to bite off their toes, a condition called "autotomy" (Wall, Devor, Inbal, Scadding, Schonfeld, Seltzer, \& Tomkiewiez, 1979). One of us (R.T.) has occasionally observed this behavior in adult rats with nigral lesions that encroached upon the cerebral peduncle. It remains to be seen whether this behavior in the nigrallesioned rat is induced by interruption of descending inhibitory influences upon spinal michanisms.

2. Any given laboratory task can be conceived as being mediated by a nonspecific mechanism (the general learning system) and one or more specific mechanism, the latter depending upon the cognitive, sensory, motor, and motivational demands of the task itself (Thompson, 1982c).

3. Attentional processes have periodically been linked to extrapyramidal (Hassler, 1978), thalamic (Wallesch, Kornhuber, Kunz, \& Brunner, 1983), limbic midbrain (Wirtshafter \& Asin, 1982), and brainstem reticular formation (Ray, Mirsky, \& Pragay, 1982) structures, most of which are components of the general learning system.

(Manuscript received August 24, 1983; revision accepted for publication December 8, 1983.) 